\title{
Factors Leading to Early Embryonic Death
}

\author{
B. R. Shah \\ Institute of Agriculture and Animal Science, Paklihawa \\ *Corresponding author: Vet.bikas@gmail.com
}

Early embryonic death is defined as the loss of embryo or conceptus which occurs between fertilization and 15 days post insemination. Early embryonic death leads to reproductive failure in animals resulting in reduced pregnancy rates, slower genetic improvement and substantial impact on farm profitability. Early embryonic death is an eloquent limiting factor for the completion of pregnancy in animals (Inskeep and Dailey, 2005). Incidence of embryonic losses is usually higher than perinatal losses. Notably, fetal development may or may not have affected by maternal infections during pregnancy (Givens and Marley, 2008). Early embryonic death occurs before the fetal calcification. Complete resorption of the embryo is usually seen during early embryonic death (Wrathall, 1975). Embryonic or fetal death leads to resorption, mummification, maceration or abortion. Gestational age, cause of death, and source of progesterone for pregnancy maintenance are the factors that impacts the outcome of the embryonic or fetal death (Givens and Marley, 2008). Most often, early embryonic death, post implantation is due to the uterine environment rather than fetal development (Clark et al., 1986). Dead embryos, between the time of implantation and calcification, are also resorbed. If the entire litter is lost, the dam will return to service at an irregular interval, usually 5 to 10 days post pregnancy loss (Wrathall, 1975) and pregnancy is continued if even a single number of embryo remains (Christianson, 1992). In a farm or within a particular litter, more than one type of embryo or fetal death can be found, but accurate classification is important for further better investigation (Christianson, 1992). Diagnosis is usually very difficult; as the agent or cause of embryonic death is no longer present while investigation is taking place. So, it is important to be aware of variety of causes of embryonic death that helps to rule out the particular problems that can be diagnosed and treated (Christianson, 1992). Proper history such as vaccination status, feed changes, housing, environmental temperature and so forth should be taken, that helps to narrow down the potential list of problems to consider and root cause can be found.

Keywords: Early embryonic death, Embryonic, Fetal death, Gestation, Pregnancy

\section{INTRODUCTION}

Early embryonic death has a disastrous impact on the fertility of domestic animals. It mostly occurs during days of fertilization and during the process of implantation. Causes of early embryonic death can be divided into infectious and non-infectious categories. Major attention has often been given to the infectious causes, but non-infectious causes probably accounts for more than $70 \%$ of the cases of early embryonic death (Vanroose dt.al, 2000). Embryonic environment can be infected by specific and non-specific uterine pathogens. Specific uterine infections are caused by various bacteria, virus, protozoa and possibly mycoplasma, which enter the uterus through haematogenous route or via the vagina. Non-specific pathogens are mostly bacteria that enter the uterus by ascending infection. Uterine pathogens may cause early 
embryonic death directly by contaminating the uterine environment leading to endometritis or by direct cytolytic effect on the embryo and directly bysystemic effects via septicemias, viremias or toxemias on the dam (Blackwell et.al. 1987). Non-infectious causes of early embryonic death are chromosomal aberrations, external factors e.g. high ambient temperature, nutritional factors and maternal factors. Causes of early embryonic death are multifactorial and very difficult to diagnose (Vanroose et.al., 2000). A useful procedure in differentiating infectious and noninfectious causes of early embryonic death is to test the presence of immunoglobulins in uterine contents by immunodiffusion (Chaniago et.al., 1978). If immunoglobulin is present, further tests for antibodies to specific agents are performed (Christianson, 1992). The overall objective of this study is to identify the factors leading to early embryonic death in animals. Specific objectives to study the infectious and non-infectious causes of early embryonic death in animals and to study the nutritional, maternal and other factors leading to early embryonic death in animals.

\section{MATERIALS AND METHODS}

Comprehensive review of various articles, journals, literatures and websites were done to find out the major factors leading to early embryonic death in animals as follows:

\section{Infectious Causes}

Infection of the embryonic environment (oviduct and uterus) can be caused by specific and nonspecific pathogens such as Toxoplasma gondii, Campylobacter spp. Bovine viral diarrhea virus (BVDV), etc. These infection results in inflammatory products which must be eliminated before the embryo descends into the uterus. Particularly in older animals (e.g., the mare), this uterine clearance can be impaired. Acute endometritis, after mating or artificial insemination, has direct effect on the embryonic environment and in severe cases is accompanied by the production of luteolytic substances such as prostaglandins (De Winter et.al., 1995, van). Uterine infection due to bacteria mostly causes diffused and severe purulent inflammation while viral infection, in most cases is characterized by a necrotizing endometritis leading diffused and total lymphocytic and plasmacytic changes in the endometrium.Chronic endometritis involves morphological and functional changes in the uterus besides inflammation. The layers of fibrous tissue are deposited around endometrial glands, which results in a deficiency of functional glands, which deprive the embryo of the protein-rich exocrine secretion. Infections of the embryo can take place at two important phases in the embryonic development; before hatching and after hatching.

\section{Before Hatching (Zona Pellucida-Intact Embryos)}

Of all pathogens, viruses are the most insidious and dangerous type of infection for the earlystage embryo. Viral infection of the zona pellucida-intact embryocan already have taken place before fertilization during maturation of the oocyte. Viruses, e.g. bovine herpes virus 1 BHV -1 and BVDV, might be present in follicular fluid or granulosa cells of bovine oocytes (Bielanski et.al., 1993), and can also contaminate the embryos by sticking to the glycoprotein layer, which surrounds the oocyte, the so-called zona pellucida. In persistently-infected cattle, BVDV antigen has even been detected inside the oocyte (Brownlie et.al. 1997). Virus adhering to the zona pellucida or to the fertilizing spermatozoon might be introduced into the oocyte by the sperm track in the zona pellucida created at the time of fertilization (Bowen, 1979). Passive migration 
of virus through the meshes in the zona pellucida is highly unlikely to occur, since particles with a diameter of 40 and $200 \mathrm{~mm}$ comparable size as BVDV and BHV1 remain stuck in the peripheral part of the zona pellucida (Vanroose, 1999). One of the smallest viruses, the porcine parvovirus, could pass the zona pellucida in pigs is seen in only one report ever (Bolin et.al. 1983). After fertilization, the zona pellucida can be considered as an effective barrier for virus penetration (Stringfellow et.al., 1991; Vanroose et.al., 1999a). However, death of a zona pellucida-intact embryo can occur because of a hostile uterine environment, at the early embryonic stages.

\section{After Hatching}

Embryos hatch from the zona pellucida at 8-9 days in cattle, 7-8 days in sheep and 6-7 days in pigs. In the horse, a non-cellular membrane envelops the early equine conceptus which resembles the zona pellucida is gone by day 20. After hatching or after removal of the zona pellucida, the embryonic cells are susceptible to some infectious agents (Wrathall and Sutmoller, 1998). For example, zona pellucida-free bovine morula and blastocysts are susceptible to bovine herpesvirus-1 (Bowen et.al., 1985; Bielanski et.al., 1987; Vanroose et.al., 1997) and BVDV (Brock and Stringfellow, 1993; Vanroose et.al., 1998), but not to bovine parvovirus (Bowen, 1979). Recent research on embryo- pathogen interactions has mainly been performed in cattle, by exposing in vivo derived or in vitro produced embryos to specific pathogens in vitro (Wrathall and Sutmoller, 1998; Vanroose, 1999).

Besides these in vitro studies, earlier in vivo studies have shown that viral uterine infections can result in extensive viral replication in embryonic cells after hatching and implantation. In addition, cells undergoing quick division, as occurs in embryos, are particularly susceptible to the replication of certain viruses (Bowen, 1979). The outcome of such an infection can either be cytolytic or non-cytolytic. Both can result in early embryonic death, but a non-cytolytic infection can also cause chromosomal damage and induce embryonic cells to divide more slowly. This retardation in cell division occurs during the critical phase of organogenesis. Consequently, viral infection of embryos may result in the development of congenital malformations.

After implantation, the haematogenous route of uterine infection becomes more important, since both endometritis and a direct cytolytic effect on the embryo are possible.

\section{Non-infectious Causes}

Chromosomal aberrations are a major cause of early pregnancy failure in animals (King, 1990). A range of misalliances can occur during the pairing of the haploid parental chromosome sets at the time of fertilization, which are subsequently lethal to the embryo. Chromosomal abnormalities may also originate by penetration of more than one sperm cell (polyspermia). Mixoploidy, polyploidy and haploidy are all aberrations that are encountered frequently in in vitro produced embryos (Kawarsky et.al., 1996; Viuff et.al., 1999) but it has not been investigated yet whether this could be a cause for the higher embryonic death rates, which are observed after the transfer of in vitro-produced bovine embryos (Van Soom et.al., 1994). King (1990) reported that chromosomal abnormalities may account for approximately $20 \%$ of the total embryonic and fetal loss. Sometimes an enzyme deficiency results in early embryonic death, e.g., 
deficiency of uridine monophosphate synthetase (DUMPS) in cattle, which is an autosomal recessive disorder (Schwenger et.al., 1993).

\section{External Factors}

\section{High Environmental Temperatures}

High environmental temperatures during the first months of gestation can also have inimical effects on the embryo (DelaSota et.al., 1998). The mechanism for this effect has been explained by a direct damaging effect of a high uterine temperature on the embryo and by the shunting of blood away from the uterus to the periphery in an attempt to maintain body temperature, resulting in a reduced nutrient load (Dziuk, 1992).

\section{Specific Nutritional Deficiencies or Malnutrition}

Specific nutrient deficiencies or malnutrition can have a negative effect on the embryo. Especially a severe deficiency of vitamins (vitamin A) or other nutrients $(\mathrm{Cu}, \mathrm{Zn}, \mathrm{I})$ that serve as regulators of metabolism can cause early embryonic death (Graham et.al., 1995). Malnutrition or a severe negative energy balance may affect the follicular development, the quality of the oocyte, and the secretory and motile activity of the oviduct which is the place of the fertilization process. These findings demonstrate that nutrition affects the very early stages of conceptus (Butler and Smith, 1989; Foxcroft, 1997).

\section{Stress}

Stress has a harmful effect on reproductive efficiency in animals (Dobson and Smith, 1995). Stressors (e.g. transport, mechanical injury, isolation, pain, changes in blood pressure, etc) affect the reproductive function via actions at the hypothalamic level $(\mathrm{GnRH})$ or at the ovarian level (progesterone).

\section{Environmental Toxicants, Teratogenic Compounds and Mycotoxins}

Environmental toxicants, teratogenic compounds and mycotoxins can have drastic adverse effects on the survival of embryos when ingested at crucial early stages of gestation (Christianson, 1992; Brendemuehl et.al., 1994).

\section{Maternal Factors}

\section{Hormonal Imbalance}

Progesterone is necessary for the maintenance of pregnancy. A deficiency of progesterone caused by primary luteal insufficiency has been reported as a cause of early embryonic death, but is probably not of frequent occurrence (Wathes, 1992; Mann et.al., 1998). 


\section{Disturbance of the Embryo-maternal Interactions}

Disturbance of the embryo-maternal interactions can result in embryonic loss. Before implantation, embryonic signaling is necessary for maternal recognition of pregnancy. This commences the hormonal changes, which are needed to evoke the transformations in uterus necessary for implantation (Gandolfi et.al., 1992; Geisert et.al., 1992; Hansen, 1997).

\section{Insufficient Uterine Space}

Embryonic loss is resulted from insufficient embryonic loss (Allen, 1992; Dziuk, 1992). The presence of extra embryo, more than one, in cattle and horses and more than 20-25 embryos in swine causes a competition between the embryos for access to the endometrium. For example, in the mare, natural embryo reduction of twin embryos (10-20\% of the pregnancies) occurs in a majority of the cases, especially between the second and sixth week of pregnancy (Ginther, 1989).

\section{Age of Dam}

Aged animals have minimal follicular activity and oocyte quality resulting in a reduction of the developmental competence of embryos. Furthermore, the quality of the endometrium is deteriorating with increasing age.

\section{Inbreeding}

Inbreeding has been reported as a cause of early embryonic death (Hanzen et.al., 1999). It has also been proven that the early embryonic death differs from breed to breed.

\section{CONCLUSION}

The death of embryo between 1-15 days post insemination, before fetal calcification, is called early embryonic death. It has high impact on farm profitability. Early embryonic death leads to resorption, mummification, maceration or abortion. The causes of early embryonic death may be infectious or non-infectious. Infectious causes includes specific and non-specific uterine pathogens while non-infectious causes includes chromosomal aberrations, maternal factors; hormonal imbalance, age of dam, insufficient uterine space, embryo-maternal interaction disturbances and inbreeding, and other factors; environmental temperature, nutritional deficiency, stress and toxicants. Although it is difficult to diagnose the cause of early embryonic death, it is necessary for proper diagnosis and elimination of early embryonic death as it is limiting factor for the successful pregnancy, and disastrously affecting the animal farms and overall animal industry economy. 


\section{REFERENCES}

A. E., and Sutmoller, P. (1998). Potential of embryo to control transmission of. In Stringfellow, D. A., and Seidel, S. M. Eds., Manual of the International Embryo Transfer Society, pp. 17

Allen, W. R. (1992). The diagnosis and handling of early gestational abnormalities in the mare. Animal Reproduction Science, 28, pp. 31-38.

Bielanski, A., Loewen, K. K., DelCampo, M., Sirard, M., and Willadsen, S. (1993). Isolation of bovine herpesvirus-1 BHV-1 and bovine viral diarrhea virus BVDV in association with the in vitro production of bovine embryos. Theriogenology, 40, pp. 531-545.

Bielanski, A., Singh, E. L., and Hare, W. C. D. (1987). The in vitro exposure to bovine rhinotracheitis virus of zona pellucida-micromanipulated bovine embryos with zona pellucida damaged or removed, Theriogenology, 28, pp. 495-501.

Blackwell, T. E., Werdin, R. E., Eisenmenger, M.E., et.al., (1987). Goitrogenic effects in offspring of swine fed sulfadimethoxine and ormetroprim in late gestation. Journal of Animal Veterinary Medicine Association, 194, pp. 519-523.

Bolin, S. R., Turek, J., Runnels, L., and Gustafson, D. P. (1983). Pseudorabies virus, porcine parvovirus and porcine enterovirus interactions with the zona pellucida. Am. J. Vet. Res, 44, pp. 1036-1039.

Bowen, R. A. (1979). Viral infections of mammalian preimplantation embryos. Theriogenology, 11 , pp. $5-15$.

Bowen, R. A., Elsden, R. P., and Seidel, G. E. (1985). Infection of early bovine embryos with bovine herpesvirus-1. Am. J. Vet Res., 46, pp. 1095-1097.

Brendemuehl, J. P., Boosinger, T. R., and Shelby, R. A. (1994). Influence of endophyte-infected tall fescue on cyclicity, pregnancy rate and early embryonic loss in the mare. Theriogenology, 42, pp. 489-500.

Brock, K. V., and Stringfellow, D. A. (1993). Comparative effects of cytopathic and noncytopathic bovine viral diarrhea virus on bovine blastocysts. Theriogenology, 39, pp. 196.

Brownlie, J., Booth, P. J., Stevens, D. A., and Collins, M. E., (1997). Expression of noncytopathogenic bovine viral diarrhoea virus BVDV in oocytes and follicles of persistently infected cattle. Vet. Rec., 141, pp. 335-337.

Butler, W. R., and Smith, R. D., 1989. Interrelationships between energy balance and post partum reproductive function in dairy cattle. J. Dairy Sci., 72, pp. 767-783.

Chaniago, T. D., Watson, D. L., Owen, R. A., et al. (1978). Immunoglobulin in blood serum of foetal pigs. Aust Vet J, 54, pp. 30-33.

Christianson, W. T. (1992). Stillbirths, mummies, abortions, and early embryonic death. Vet. Clin. North Am., 8, pp. 623-639.

Clark, L. K., D' Allaire, S., and Leman, A. D. (1986). Reproductive System. InLeman, A. D., Straw, B., Glock, R. D., et al. Diseases of Swine, Ames, Iowa State University Press, ed pp.

De Winter, P. J., Verdonck, M., de Kruif, A., Devriese, L.A., and Haesebrouck, F. (1995). Bacterial endometritis and vaginal discharge in the sow: prevalence of different bacterial species and experimental reproduction of the syndrome. Anim. Reprod. Sci., 37, pp. 325335 . 
DelaSota, R. L., Burke, J. M., Risco, C. A., Moreira, F., DeLorenzo, M. A., and Thatcher, W. W. (1998). Evaluation of timed insemination during summer heat stress in lactating dairy cattle. Theriogenology, 49, pp. 761-770.

Dobson, H., and Smith, R. F. (1995). Stress and reproduction in farm animals. J. Reprod. Fertil., Suppl., 49, pp. 451-461.

Dziuk, P. J. (1992). Embryonic development and fetal growth. Anim. Reprod. Sci., 28, pp. 299308.

Foxcroft, G. R. (1997). Mechanisms mediating nutritional effects on embryonic survival in pigs. J. Reprod. Fertil., Suppl., 52, pp. 47-61.

Gandolfi, F., Brevini, T. A. L., Modina, S., and Passoni, P. (1992). Early embryonic signals: embryo-maternal interactions before implantation. Anim. Reprod. Sci., 28, pp. 269-276.

Geisert, R. D., Short, E. C., and Zavy, M. T. (1992). Maternal recognition of pregnancy. Anim. Reprod. Sci., 28, pp. 287-298.

Ginther, O. J. (1989). Twin embryos in mares II: post fixation embryo reduction. Equine Vet. J., 21, pp. 171-174.

Givens, M. D., and Marley, M. S. D. (2008). Infectious causes of embryonic and fetal mortality. Theriogenology, 70, pp. 270-285.

Graham, T. W., Giri, S. N., Daels, P. F., Cullor, J. S., Keen, C. L., Thurmond, M. C., Dellinger, J. D., Stabenfeldt, H. H., and Osburn, B. I. (1995). Associations among prostaglandines F2alpha, plasma zinc, copper and iron concentrations and fetal loss in cows and mares. Theriogenology, 44, pp. 379-390.

Hansen, P. J. (1997). Interactions between the immune system and the bovine conceptus. Theriogenology, 47, pp. 121-130.

Hanzen, C. H., Drion, P. V., Lourtie, O., Depierreux, C., and Christians, E. (1999). La mortaliteembryonnaire: Aspect cliniques et facteursetiologiques dans 1 espece bovine. Ann. Med. Vet., 143, pp. 91-118.

Inskeep, E. K., and Dailey, R. A. (2005). Embryonic Death in Cattle. Veterinary Clinics, Food Animal, 21, pp. 437-461.

Kawarsky, S. J., Basrur, P. K., Stubbings, R. B., Hansen, P. J., and King, W. A. (1996). Chromosomal abnormalities in bovine embryos and their influence on development. Biol. Reprod., 54, pp. 53-59.

King, W. A. (1990). Chromosome abnormalities and pregnancy failure in domestic animals. $A d v$. Vet. Sci. Comp. Med., 34, pp. 229-250.

Mann, G. E., Lamming, G. E., and Payne, J. H. (1998). Role of early luteal phase progesterone in control of the timing of the luteolytic signal in cows. J. Reprod. Fertil., 113, pp. 47-51.

Schwenger, B., Schober, S., and Simon, D. (1993). DUMPS cattle carry a point mutation in the uridine monophosphate synthase gen. Genomics, 16, pp. 241-244.

Stringfellow, D. A., Riddell, K. P., and Zurovac, O. (1991). The potential of embryo transfer for infectious disease control in livestock. N. Z. Vet. J., 39, pp. 8-17.

Van Soom, A., Mijten, P., Van Vlaenderen, I., Van Den Branden, J., Mahmoudzadeh, A.R., and de Kruif, A. (1994). Birth of double-muscled Belgian Blue calves after transfer of in vitro produced embryos into dairy cattle. Theriogenology, 41, pp. 855-867.

Vanroose, G. (1999). Interactions of bovine herpesvirus-1 and bovine viral diarrhea virus with bovine gametes and in-vitro-produced bovine embryos. PhD dissertation, University of Gent, Belgium. 
Vanroose, G., Kruif, A. de., and Van Soom, A. (2000). Embryonic mortality and embryopathogen interactions. Animal Reproduction Science, 60-61, pp. 131-143.

Vanroose, G., Nauwynck, H., Van Soom, A., Vanopdenbosch, E., and de Kruif, A. (1997). Susceptibility of zona-intact and zona-free in vitro produced bovine embryos at different stages of development to an infection with bovine herpesvirus-1. Theriogenology, 47, pp. 1389-1402.

Vanroose, G., Nauwynck, H., Van Soom, A., Vanopdenbosch, E., and de Kruif, A. (1998). Replication of cytopathic and noncytopathic bovine viral diarrhea virus in zona-free and zona-intact in vitro produced bovine embryos and the effect on embryo quality. Biol. Reprod., 58, pp. 857-866.

Vanroose, G., Nauwynck, H., Van Soom, A., Ysebaert, M. T., Charlier, G., Van Oostveldt, P., and de Kruif, A. (1999a). Why is the zona pellucida of in vitro produced bovine embryos an efficient barrier for viral infection? A scanning electron and confocal laser microscopic study. Theriogenology, 51, pp. 276.

Viuff, D., Rickords, L., Offenberg, H., Hyttel, P., Avery, B., Greve, T., Olsaker, I., Williams, J. L., Callesen, H., and Thomsen, P. D. (1999). A high proportion of bovine blastocysts produced in vitro are mixoploid. Biol. Reprod., 60, pp. 1273-1278.

Wathes, D.C. (1992). Embryonic mortality and the uterine environment. J. Endocrinol., 134, pp. 321325.

Wrathall, A. E. (1975). Reproductive Disorders in Pigs. Farnham Royal, England. Commonwealth Agricultural Bureaux. 